\title{
STRUCTURE AND ABRASIVE WEAR RESISTANCE OF DEPOSITED METAL HARDENED WITH CARBIDES OF DIFFERENT TYPES
}

\author{
I.A. RYABTSEV ${ }^{1}$, A.I. PANFILOV ${ }^{2}$, A.A. BABINETS ${ }^{1}$, I.I. RYABTSEV ${ }^{1}$, \\ G.N. GORDAN ${ }^{1}$ and I.L. BABIJCHUK ${ }^{1}$ \\ ${ }^{1}$ E.O. Paton Electric Welding Institute, NASU \\ 11 Bozhenko Str., 03680, Kiev, Ukraine. E-mail: office@paton.kiev.ua

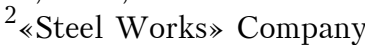

50 Mir Ave., of. 32, 50069, Krivoj Rog, Dnepropetrovsk Distr., Ukraine. E-mail: ogs@steel-work.net

\begin{abstract}
Wear resistance was studied at wearing by fixed and unfixed abrasive of metal deposited with PP-AN192 flux-cored wire (strengthened by titanium carbides) and by Hardface HC-O flux-cored wire (strengthened by chromium carbides). It is found that both the deposited metal types, despite the different total content of alloying elements (30\% for Hardface HC-O and $10 \%$ for PP-AN192), have approximately the same wear resistance. Structure of deposited metal of both the types consists of martensite, small quantity of residual austenite and carbides of different composition. Here, the high wear resistance of metal deposited with PP-AN192 flux-cored wire is attributable to the fact that titanium carbide contained in it is greatly superior in terms of hardness and wear resistance to chromium carbides, hardening the metal deposited with Hardface HC-O flux-cored wire. 10 Ref., 4 Tables, 6 Figures.
\end{abstract}

Ke y words: deposited metal, flux-cored wires, abra sive wear, wear resistance, microstructure, carbides

Strong carbide formers, namely chromium, titanium, vanadium, tungsten, etc., are used as the main alloying elements in surfacing materials, which are applied for reconditioning and hardening of parts exposed to different kinds of intensive abrasive wear in service [1-7]. They form hard phases such as carbides, carbonitrides, carboborides, etc. in the deposited metal structure. Being the hardest component of deposited metal, these phases largely determine its wear resistance [1-4]. Table 1 gives the composition, crystalline structure and some properties of carbides of above-mentioned metals [8].
Carbides can be primary or secondary, and can also form various carbide (boride) eutectics. These carbide precipitates solidify at different temperatures and are differently arranged in the deposited metal matrix, consisting of austenite and products of its transformation at cooling. Nature of forming carbides and their arrangement in the structure, in their turn, depend on deposited metal composition, as well as temperature of weld pool melt overheating and its cooling conditions. Carbide arrangement and their precipitate shape have a marked influence on material properties: their wear resistance, hardness and impact resistance.

At other equal conditions, the higher the carbide hardness, the higher the deposited metal

Table 1. Properties of carbides of the main carbide-forming metals [8]

\begin{tabular}{||c|l|c|c|c||}
\hline \hline Carbide & \multicolumn{1}{|c|}{ Crystalline lattice type } & Microhardness, $\mathrm{MPa}$ & Density, $\mathrm{g} / \mathrm{cm}^{3}$ & Melting temperature, ${ }^{\circ} \mathrm{C}$ \\
\hline $\mathrm{Fe}_{3} \mathrm{C}$ & Rhombic (orthorhombic) & $8400-8600$ & 7.62 & 1650 \\
\hline $\mathrm{Cr}_{3} \mathrm{C}_{2}$ & Orthorhombic & 22800 & 6.68 & 1895 \\
\hline $\mathrm{Cr}_{7} \mathrm{C}_{3}$ & Hexagonal (trigonal) & 22000 & 6.90 & 1780 \\
\hline $\mathrm{Cr}_{23} \mathrm{C}_{6}$ & Complex cubic & 16500 & 7 & 1520 \\
\hline $\mathrm{W}_{2} \mathrm{C}$ & Hexagonal & 30000 & 17.15 & 2850 \\
\hline $\mathrm{WC}$ & Hexagonal & 17000 & 15.70 & 2600 \\
\hline $\mathrm{VC}$ & FCC & 27000 & 5.36 & 2830 \\
\hline $\mathrm{TiC}$ & FCC & 32000 & 4.93 & 3100 \\
\hline $\mathrm{NbC}$ & FCC & 24000 & 7.78 & 3490 \\
\hline
\end{tabular}


Table 2. Deposited metal composition (wt.\%) and hardness

\begin{tabular}{|l|c|c|c|c|c|c||}
\hline \multicolumn{1}{|c|}{ Flux-cored wire } & $\mathrm{C}$ & $\mathrm{Mn}$ & $\mathrm{Si}$ & $\mathrm{Cr}$ & $\mathrm{Ti}$ & Mardness HRC \\
\hline Hardface HC-O & 3.60 & 1.32 & 1.47 & 25.90 & - & 0.30 \\
\hline PP-AN192 & 1.43 & 0.65 & 0.72 & 4.62 & 3.42 & 0.47 \\
\hline
\end{tabular}

wear resistance. If one and the same element forms several types of carbides, differing in their composition, hardness and crystalline structure, the properties of metal deposited with these carbides will differ.

Here, it is necessary to take into account the fact that surfacing materials are, as a rule, alloyed by several elements, leading to formation in the deposited metal of carbides, in which the main carbide former is substituted by other elements that may affect the forming carbide properties.

Structural condition of deposited metal matrix has a strong influence on its wear resistance. On the one hand, it should readily retain the hard phase particles, and should prevent their spalling during wearing. On the other hand, the matrix proper should have sufficiently high hardness and good wear resistance. Experience shows that highalloyed martensite-austenite matrix gives better results at intensive abrasive wear [1, 3, 7, 9].

Residual austenite content in the deposited metal structure depends on the intensity of shock loads which accompany wearing. Here, the higher the shock load intensity, the greater the quantity of residual austenite that should be present in the deposited metal structure, providing sufficient toughness and ductility to the latter [1]. By some data [9], carbides are more readily retained by the alloy matrix, if a coherent bond or strong conjugation develops between the carbide and matrix crystalline lattices on carbidematrix interface [10].

Thus, such a quantity of alloying elements and carbon should be added to the surfacing material, which ensures producing a strong and sufficiently ductile matrix of the deposited metal and the required content of the hard phase (carbides, carbonitrides, carboborides, etc.) in the latter.

In view of the above, the objective was set to evaluate the influence of structure and carbides of different type on deposited metal wear resistance at abrasive wear with fixed and unfixed abrasive.

Wear resistance and structure of two types of deposited metal designed for service under abrasive wear conditions was studied and compared. One was hardened with chromium carbides, the other - with titanium carbides and carboni- trides. Sample surfacing was performed with selfshielded flux-cored wires Hardface $\mathrm{HC}-\mathrm{O}$ of $1.6 \mathrm{~mm}$ diameter produced by Welding Alloys, and PP-AN192 of $2.0 \mathrm{~mm}$ diameter produced by PWI. Table 2 gives the deposited metal composition and hardness. As is seen from the Table, the total content of alloying elements in the metal deposited with Hardface $\mathrm{HC}-\mathrm{O}$ wire exceeds $30 \%$, and in the metal deposited with PP-AN192 wire it is on the level of $10 \%$.

To study the wear resistance, the above fluxcored wire grades were used to perform singleand two-layer surfacing of blanks from steel St3, from which $50 \times 50 \times 10 \mathrm{~mm}$ samples were cut out, in which the deposited surface was polished. Wear resistance studies were conducted by two procedures: at friction of surfaced samples on unfixed abrasive to GOST 23.208-79 and, for comparison, at friction on fixed abrasive.

During testing at friction on unfixed abrasive, sample 4 is pressed against rotating rubber disc 1 with its deposited surface with force $P$ ( Figure 1). Quartz sand 5 is fed onto rubber disc 1 from hopper 6 . At rotation the rubber disc entraps the sand which leads to wear of sample 4.

Quartz sand was dried before testing, resulting in its not more than $0.16 \%$ humidity. To remove sand particles embedded into the rubber disc, it was treated with sandpaper (Type 2 to GOST 6456-75) with \#8P grit (DSTU 3647-71)

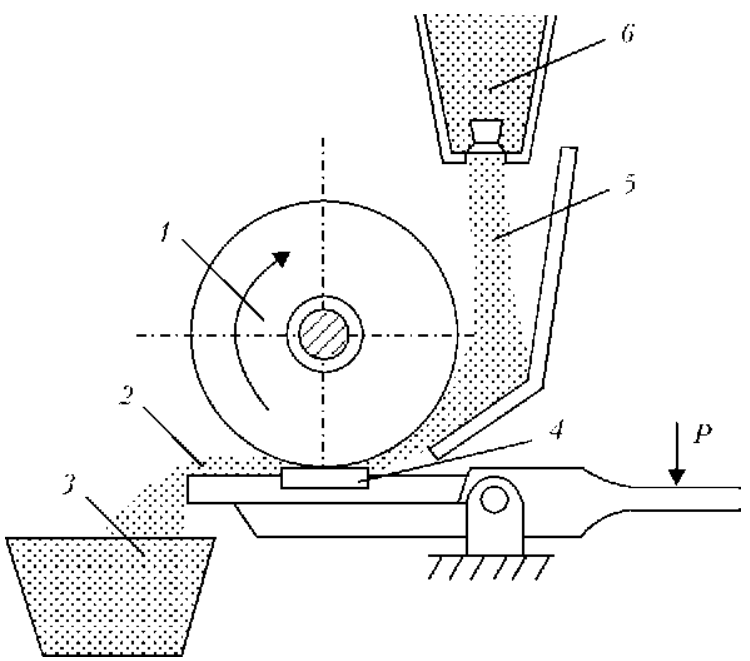

Figure 1. Block-diagram of the unit for studying abrasive wear by unfixed abrasive: 1 - rubber disc; 2 - used quartz sand; 3 - hopper for collection of used abrasive; 4 studied sample; 5 - fresh quartz sand; 6 - hopper with fresh quartz sand 


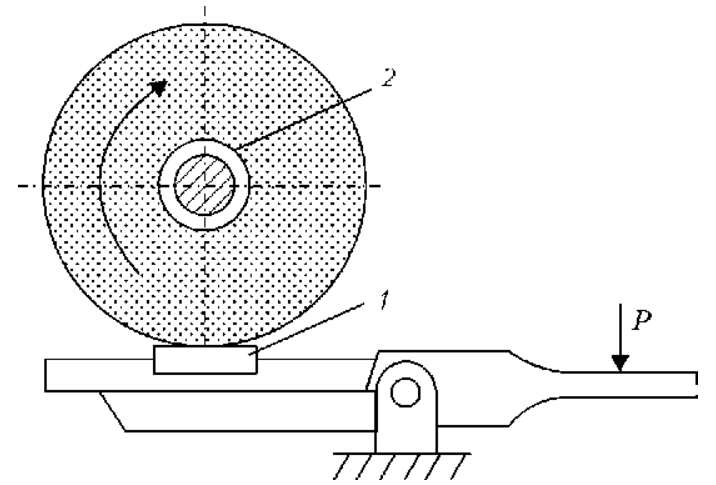

Figure 2. Block diagram of the unit for studying sample wear by rigidly fixed abrasive: 1 - sample; 2 - abrasive disc

before each test. The sandpaper was fixed in a holder in the form of a flat steel plate.

Rubber disc diameter was 48 to $50 \mathrm{~mm}$, its width was $15 \pm 0.1 \mathrm{~mm}$. Friction mode was as follows: hold-down pressure $P=2.4 \mathrm{~N}$, disc rotation speed of $25 \mathrm{~m} / \mathrm{min}$; quartz sand particle size was 200 to $1000 \mu \mathrm{m}$. Wear was evaluated by sample mass loss with up to $2 \cdot 10^{-4} \mathrm{~g}$ accuracy.

Comparative studies of wear at friction on fixed abrasive were conducted in the unit, the schematic of which is given in Figure 2. Disc of $150 \mathrm{~mm}$ diameter and $8 \mathrm{~mm}$ width from SM-2 electrocorundum of medium-soft hardness on 7K15 ceramic binder was used as wearing element. Electrocorundum grain size is equal to $250-315 \mu \mathrm{m}$, linear friction speed is $100 \mathrm{~m} / \mathrm{min}$ with $1.5 \mathrm{~N}$ load in the contact zone. Wear was evaluated by sample mass loss with up to $2 \cdot 10^{-4} \mathrm{~g}$ accuracy.

Results of testing by both the procedures are given in Table 3 .

As shown by the data given in Table 3, twolayer surfacing with both types of flux-cored wires provides a higher wear resistance. This is attributable to the fact that the first deposited layer composition differs from the optimum one as a result of mixing with the base metal. It should be noted that, despite the different alloying degree, wear resistance of deposited metal of both the types is at approximately the same level. Apparently, the wear resistance is influenced by deposited metal structure, content and properties of carbides forming in it.

Microstructure of deposited metal of two compositions and of transition zone on the deposited metal-base metal boundary (steel St3) was studied.

Sample etching was conducted in stages: first, electrolytically, in $20 \%$ solution of chromic acid. This reagent reveals the deposited metal structure. Then, chemical etching of samples in $4 \%$ nitric acid solution was performed to reveal the base metal structure.

Microstructure of metal deposited with Hardface HC-O flux-cored wire, consists of martensite-austenite matrix, primary carbides in the form of large «pencil-type» plates, secondary carbides with hexagonal faceting with clear-cut in-

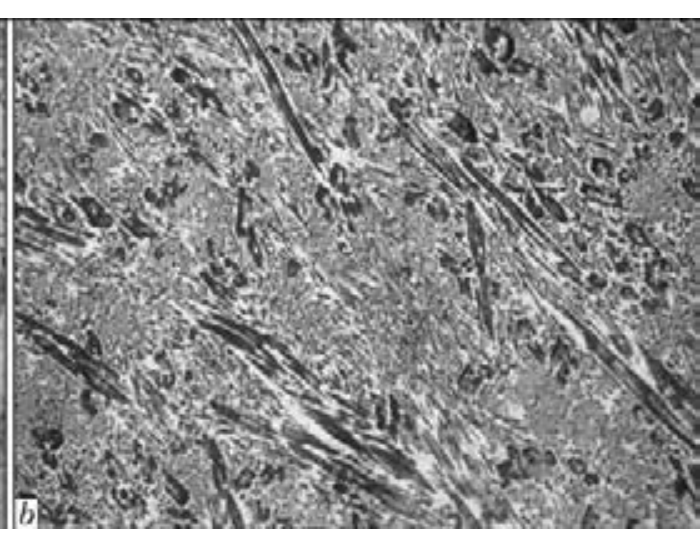

Figure 3. Microstructure of the transition zone $(a)$ and metal $(b)$ deposited by Hardface HC-O flux-cored wire

Table 3. Results of wear resistance testing of deposited metal at friction on unfixed and fixed abrasive

\begin{tabular}{||c|c|c|c|c|c||}
\hline \multirow{2}{*}{ Material grade } & \multirow{2}{*}{$\begin{array}{c}\text { Quantity of deposited } \\
\text { layers }\end{array}$} & \multicolumn{2}{|c|}{ Mass loss at wear, g } & $\begin{array}{c}\text { Wear resistance at } \\
\text { friction on unfixed } \\
\text { abrasive }\end{array}$ & $\begin{array}{c}\text { Wear resistance at } \\
\text { friction on fixed } \\
\text { abrasive }\end{array}$ \\
\cline { 2 - 6 } & Onf & 0.030 & 0.047 & 4.03 & 2.76 \\
\cline { 2 - 6 } Hardface HC-O & Two & 0.028 & 0.019 & 4.32 & 6.84 \\
\hline \multirow{2}{*}{ PP-AN192 } & One & 0.027 & 0.042 & 4.48 & 3.09 \\
\cline { 2 - 6 } & Two & 0.024 & 0.021 & 5.04 & 6.19 \\
\hline Reference - steel 40Kh & - & 0.121 & 0.130 & 1 & 1 \\
\hline
\end{tabular}


Table 4. Dimensions of carbides of different type in metal deposited with Hardface HC-O flux-cored wire

\begin{tabular}{|c|c|c|c||}
\hline \multirow{2}{*}{ Quantity of deposited layers } & \multicolumn{2}{|c|}{ Size of hexagonal carbide side, $\mu \mathrm{m}$} & \multicolumn{2}{c|}{ Length of «pencil» type carbides, $\mu \mathrm{m}$} \\
\cline { 2 - 5 } & At fusion line & In deposited layer center & \multicolumn{2}{|c|}{ At fusion line } \\
\hline One & $15-35$ & $5-15$ & $200-350$ \\
\hline Two & $10-12$ & $20-30$ & 200 \\
\hline
\end{tabular}

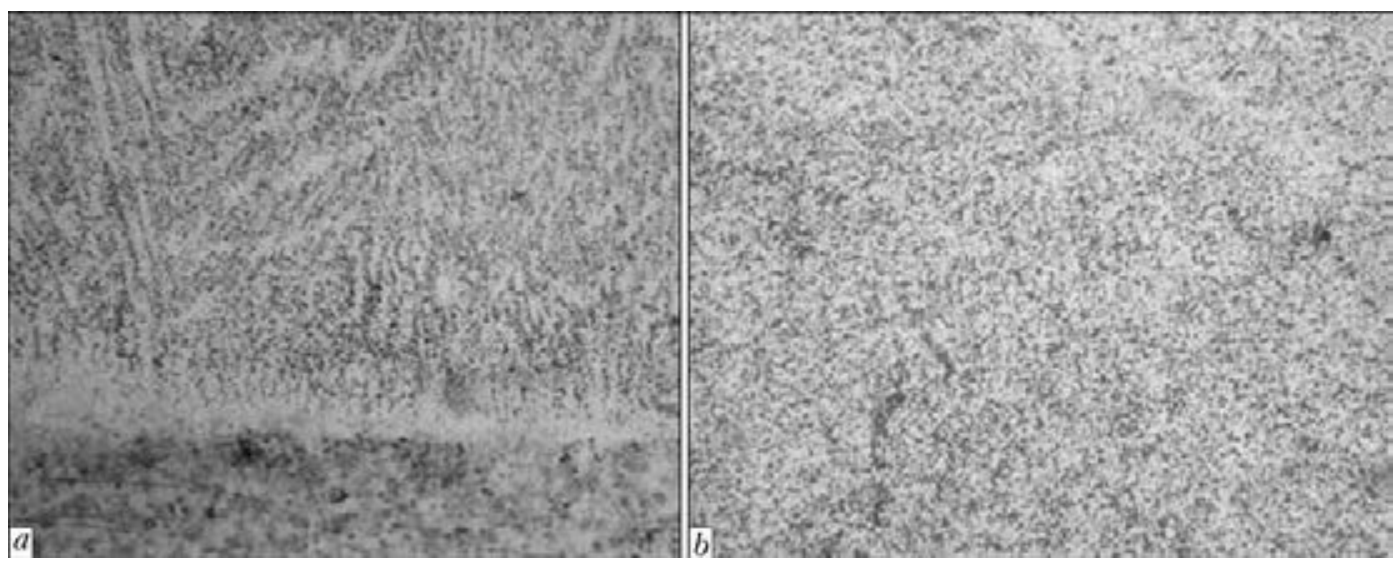

Figure 4. Distribution of iron, chromium, carbon $(a)$, manganese and silicon $(b)$ in the HAZ at surfacing of steel St3 sample with Hardface HC-O flux-cored wire

terface with the matrix, as well as carbide eutectics (Figure 3, $a, b$ ).

Carbide hardness is in the range of $H V 0.5-$ 10950-14130 MPa. Thus, in terms of hardness they can be classified as carbides of $\mathrm{Me}_{23} \mathrm{C}_{6}$ type (see Table 1). An unetchable white band from 5 to $10 \mu \mathrm{m}$ wide was detected along the joint line, the hardness of which is equal to $H V 0.5-3170-$ $3580 \mathrm{MPa}$. Deposited metal hardness in the layer
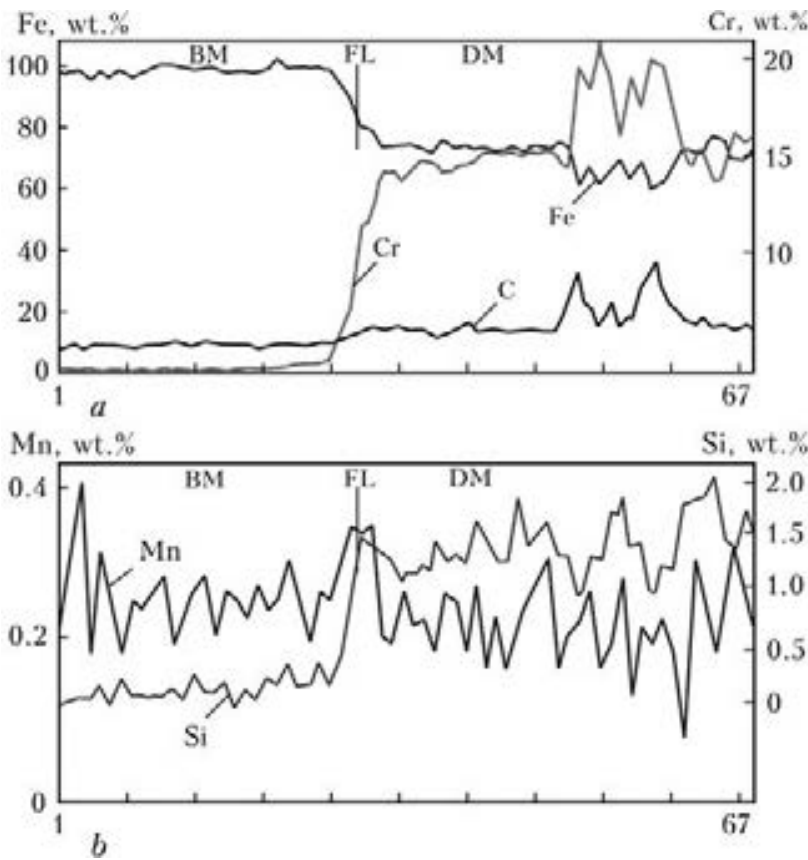

Figure 5. Distribution of iron, chromium, carbon $(a)$, manganese and silicon $(b)$ in the HAZ at surfacing of steel St3 sample with Hardface HC-O flux-cored wire center is equal to $H V 10-7420 \mathrm{MPa}$, being somewhat lower at the fusion line ( $H V 10-6730 \mathrm{MPa})$.

Median of «pencil-type» carbides and faces of hexagonal-shaped carbides was also measured (Table 4). «Pencil-type» carbides have considerable size that may lead to their spalling at wear.

Microstructure of metal, deposited with PPAN192 wire, consists of martensite and residual austenite with precipitates of very fine titanium carbides and carbonitrides (Figure 4, $a$ ). Here, in the deposited metal subsurface layers carbide
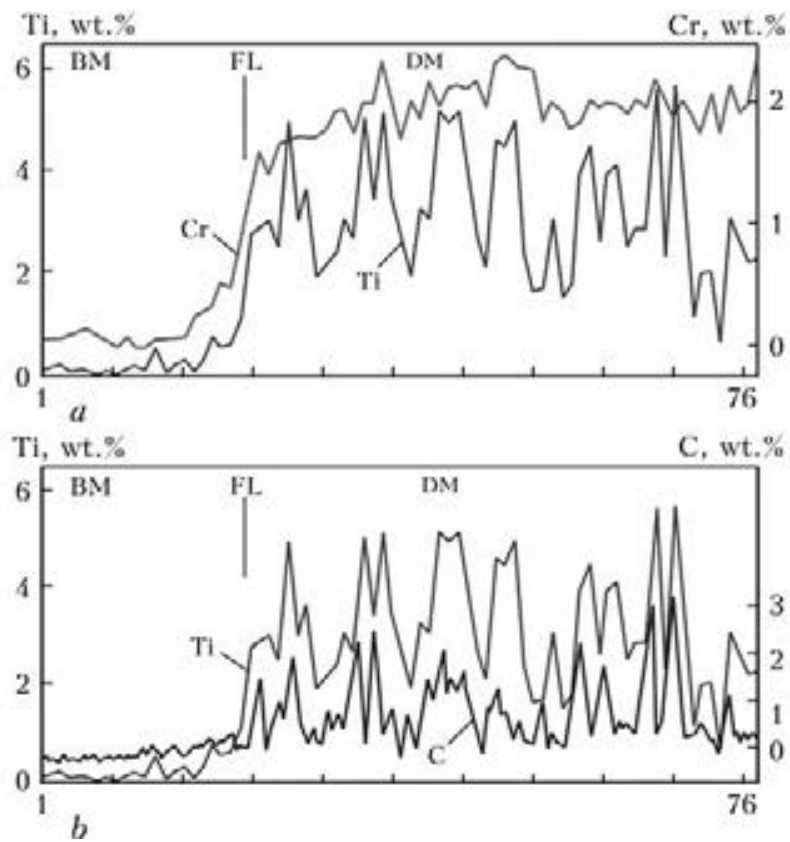

Figure 6. Distribution of chromium, titanium $(a)$, carbon and titanium $(b)$ in the HAZ in surfacing of St3 steel sample by PP-AN192 flux-cored wire 
precipitates are coarser and their quantity is greater than at the fusion line. A weakly-etching band from 5 to $20 \mu \mathrm{m}$ wide of hardness $H V 0.5-$ $3100 \mathrm{MPa}$ forms along the line of fusion with base metal. Deposited metal hardness is equal to $H V 0.5-5020-5090 \mathrm{MPa}$ at the fusion line, and to $H V 0.5-5490 \mathrm{MPa}$ in the deposited layer center, that is somewhat lower than in the metal deposited with Hardface HC-O wire. Carbide hardness could not be measured, because of their small size.

X-ray spectral microanalyzer was used to study the distribution of the main alloying elements in the fusion zone at surfacing with Hardface $\mathrm{HC}-\mathrm{O}$ (Figure 5, $a$ ) and PP-AN192 wires (Figure 6).

As is seen from Figure 5, in the metal deposited with Hardface HC-O wire chromium is partially bound into carbides, and partially alloys the matrix. In the metal deposited with PP-AN192 wire practically all the titanium is bound into carbides in 4:1 ratio with carbon. Chromium mainly alloys the deposited metal matrix (see Figure 6).

In terms of hardness, titanium carbide is greatly superior to all the three types of chromium carbides (see Table 1). More over, chromium carbides are much coarser than titanium carbides and they can spall during wear, because of their relatively low strength. Apparently, in view of these circumstances, the metal deposited with PP-AN192 wire is not inferior to metal deposited with Hardface HC-O wire in terms of wear resistance, despite the lower overall content of alloying elements.

\section{Conclusions}

1. Wear resistance at wearing by fixed and unfixed abrasive of metal deposited with Hardface
HC-O and PP-AN192 flux-cored wires was studied. It is established that both the types of deposited metal, despite the different total content of alloying elements (30\% in Hardface HC-O and $10 \%$ in PP-AN192), have approximately the same wear resistance.

2. High wear resistance of metal, deposited with PP-AN192 flux-cored wire, is attributable to the fact that titanium carbides contained in it are superior in terms of hardness and wear resistance to chromium carbides, which strengthen the metal deposited with Hardface HC-O fluxcored wire.

1. Livshits, L.S., Grinberg, N.A., Kurkumelli, E.G. (1969) Principles of alloying of deposited metal. Abrasive wear. Moscow: Mashinostroenie.

2. Khrushchov, M.M., Babichev, M.A. (1970) Abrasive wear. Moscow: Nauka.

3. Khrushchov, M.M., Babichev, M.A., Berkovich, E.S et al. (1971) Wear resistance and structure of hard deposits. Moscow: Mashinostroenie.

4. Ryabtsev, I.A., Senchenkov, I.K. (2013) Theory and practice of surfacing works. Kiev: Ekotekhnologiya.

5. Pereplyotchikov, E.F., Ryabtsev, I.A., Vasiliev, V.G. et al. (2003) Structure and properties of high-carbon high-vanadium iron-base alloys for surfacing. Metallovedenie i Termich. Obrab. Metallov, 5, 36-40.

6. Ryabtsev, I.A., Kondratiev, I.A., Zhudra, A.P. et al. (2002) Flux-cored wires for surfacing developed in PWI. Svarshchik, 2, 34-35

7. Ryabtsev, I.A., Kondratiev, I.A., Vasiliev, V.G et al. (2002) Wear resistance of deposited metal of Fe$\mathrm{C}-\mathrm{Cr}-\mathrm{Ti}-\mathrm{Mo}$ alloying system. The Paton Welding J., 4, 45-48.

8. Kiffer, R., Benezowsky, F. (1971) Hard alloys. Moscow: Metallurgiya.

9. Frumin, I.I., Ryabtsev, I.A., Golovashchuk, A.I. (1974) Influence of structural transformations on wear resistance of U25Kh6T4M carbide steel. Avtomatich. Svarka, 9, 23-25.

10. Palatnik, L.S., Papirov, I.I. (1964) Oriented crystallization. Moscow: Metallurgiya. 